\title{
Space and Place. A Morphological Perspective
}

\author{
Paolo Furia ${ }^{1}$ (iD
}

Received: 23 September 2020 / Accepted: 2 February 2021 / Published online: 18 February 2021

(c) The Author(s) 2021

\begin{abstract}
The morphological account of landscape aims to overcome the contrast between an objectivist/scientific account of space and the more qualitative/subjective account of place. It does so by actualizing the notion of landscape, which endows a materiality often overlooked in contemporary spatial theories. In this paper, I will discuss what has been called the 'space-place conundrum' by referring mostly to the human geography contemporary debate on space and place. In the following, I will retrieve Carl Sauer's morphological conception of landscape as an alternative framework aimed at rephrasing both the concepts of space and place. Landscape must be freed from the cage of the aesthetic gaze so that it can be understood as a lived and dynamic complex of interacting forms that encompass the embodied subject. In the end, I will outline the main characteristics of a morphological conception of landscape, paving the way for further inquiries.
\end{abstract}

Keywords Geography $\cdot$ Landscape $\cdot$ Morphology $\cdot$ Place $\cdot$ Space

\section{Introduction}

\subsection{Space, Place, and Landscape}

Space, place, and landscape are terms of common use, which nonetheless hide complex and stratified meanings. As the geographer John Agnew has noted: "Contrary perhaps to first appearance, space and place are fairly complex words. The Oxford English Dictionary gives over about two pages to space and around three and a half pages to place" (Agnew 2011, p. 316). There has been considerable semantic confusion within and across disciplines about the conceptual relationship of space and place. The anthropologist Setha Low identifies some conceptual patterns of connection between space and place: a first one according to which "they are separate constructs with no overlap" (Low 2013, p. 12). A second conceptualisation is that

Paolo Furia

paolo.furia@unito.it

1 Dipartimento Di Filosofia E Scienze Dell'Educazione, Università Di Torino, Torino, Italy 
"space is the more encompassing construct, while place retains its relevance and meaning but only as a subset of space" (Ibidem). In this case, Low argues, space is the objective three-dimensional extension of reality, whereas "place is defined as lived space made up of spatial practices and is phenomenologically experienced, such as the culturally meaningful space of home" (Ibidem). A third one considers place to be "the larger category encompassing a conceptually limited and more narrowly defined construct of space" (Ibidem): in this case, objective space is rather seen as a rational abstraction drawing on a prior experience of lived places. According to Low, the second conceptualisation reflects "the most common way that social scientists think about space and place" (Ibidem). Agnew confirms this idea by affirming that: "space is regarded largely as a dimension within which matter is located or a grid within which substantive items are contained" (Agnew 2011, p. 316). But, despite its popularity, it draws on a simplistic distinction between the objective (space) and the subjective (place), which does not take sufficient account of their reciprocal and constitutive connections.

Landscape is a complex and somehow ambiguous concept too. Over the past decades, scientific research on landscape "in psychology, sociology, geography, medicine, planning, philosophy, archaeology, and environmental research has intensified causing clear differentiation in the formation of landscape-theoretical approaches" (Kühne 2019, p. 1). In this multidisciplinary context, it is very easy to lack the common semantic ground which makes landscape a unitary and intuitive phenomenon for people, before being analytically framed into different disciplines. Therefore, "a basis for communication must be established" (Försters et al. 2012, p. 169). This includes "an awareness of the differences of understanding while using the same word" (Ibidem).

My paper aims to foster this communication by proposing a theoretical frame in which space, place, and landscape are inherently connected and reciprocally coimplied. My hypothesis is that morphology provides the common theoretical framework we are looking for. It is important to clarify that, before being considered as a specific discipline or subfield, morphology is a philosophical approach which runs through various disciplines, as it is very well shown by the recently published Glossary of Morphology (2021) edited by Federico Vercellone and Salvatore Tedesco. In this project, morphology is reconnected to Goethe, who stated in a very general sense that it "rests on the conviction that everything that is must also manifest and show itself" (Goethe 1987, p. 349): in this sense, "morphology is undoubtedly configured, at the same time, as a phenomenology and an ontology" (Tedesco \& Vercellone 2021, p. 337). An ontology, as it deals with "the inorganic, the vegetable, the animal, the human" (Goethe 1987, p. 349), prior to any disciplinary distinction; a phenomenology, taken in its etymological sense (phainomai - to appear), as it deals with the expressive values of things, which involve the observer into a formative relationship. ${ }^{1}$ As ontology, Goethe's morphological attitude can be labelled as

\footnotetext{
${ }^{1}$ Phenomenological approaches such as the one adopted by Merleau-Ponty (1965) consider phenomena not only as objective facts, but as forms equipped with expressive values, which involve the observer into a reciprocally formative relationship. In this sense, the phenomenological approach of Merleau-Ponty can be connected to the morphological perspective fostered by Goethe. About this topic, see Robbins (2015).
} 
realist, in the sense that it does not reduce the world to the way it appears to the consciousness; but as phenomenology, it can be labelled also as relational, for it does not absolutizes external reality, but rather it focuses on those constitutive relations "that precede the discrete being of individual entities" (Vercellone 2021, p. 1). Therefore, morphology may help to overcome both objectivism and subjectivism in sciences, by showing how both subjects and objects mutually imply each other in a process of reciprocal formation, constitution, and conditioning.

This conceptual pattern can be fruitfully used to articulate space, place, and landscape in a meaningful way. As I have pointed out, space, place, and landscape are highly complex concepts which are discussed by different disciplines. Nonetheless, in this paper, I will focus especially on human geography theoretical debates, for it is the ambit where the three concepts of space, place, and landscape are to be found together. In what follows, I will outline the mainstream position according to which space is the empty and homogeneous container of all things and place concerns the subjective and affective dimension of living and dwelling. Then, I will retrace the philosophical significance of morphology by referring to the pioneering works of Carl Sauer and David Seamon. According to a morphological account, landscape assumes the role of the third term which mediates between objective space and subjective place. In the last paragraph, I will sketch the main characteristics of space, place, and landscape according to a morphological approach, paving the way for further inquiries.

\subsection{Objective Space versus Subjective Place}

In recent decades, philosophers such as Jeff Malpas (1998, 2018) and Ed Casey (1996, 1997, 2009) have retraced the long history of the idea of space. Both have maintained that the common-sense concept of space as purely objective goes handin-hand with the modern abstraction of space as the empty, isomorph, neutral container of all things, suitable for mathematical analysis (the Cartesian grid). Instead, as Heidegger (1951) has pointed out, ancient Greeks conceived place, but not space: both Plato and Aristotle derived their conception of spatial dimensionality by consideration of the bodies, their movements, and their spatial relations. According to Malpas: "for Aristotle there can be no place or space without an enclosing body; for Plato the idea of space or place is understood always in relation to that which is received within it" (Malpas 1998, p. 28). Space was linked to a substance-dependent metaphysics that prevented it from being interpreted as sheer extension. Einstein, in his foreword to Jammer's Concepts of Space (1954), maintained that the concept of place preceded that of space because it is "psychologically simpler" (Einstein 1954 , p. XV). In order to conceive space from a scientific point of view, a surplus of abstraction is required. The absolute space of Newton, albeit surpassed by twentieth century evolutions in the conceptions of space-time, at least has the merit of accomplishing the "emancipation of space from the scholastic substance-accident scheme" (Jammer 1954, p. 2).

The first author to challenge the scholastic conception of space as dependent on bodies was the fifth century commentator on Aristotle, John Philoponus. He 
contended that space and void must be logically associated, even if it is not actually possible to find space with nothing in it at all. According to Malpas, space has been broadly identified with the vacuum since Giordano Bruno. A notion of nonfinite and non-object-dependent space was needed to represent the discovery of the infinitude of the universe and replace the former idea of the cosmos as a system of emplacement. Both rationalists and empiricists at that time conceive space as "continuous and infinite, homogeneous and isotropic" (Casey 1997, p. 200). Cartesian space in particular "lacks those specific attributes or qualities that would tie it to place as the specific setting of material bodies" (Casey 1997, p. 198). The grid of analytical geometry becomes the grid of physical nature itself: natural space is mathematized. Space as the empty container of moving objects, measurable as such, can thus be a necessary premise of modern physics. Accordingly, places are reduced to mere positions within the spatial grid. Their uniqueness and singularity, derived from their alleged typical association with a specific class of objects, is intrinsically challenged by their new constitution as replaceable sites identified through their given coordinates.

The modernist account of space then arises when modern physics' account of space is applied to the social world. This application of the attributes of absolute space to the social realm leads to what the human geographer RobertSack (1974) calls 'spatial separatism'. Spatial separation is "the notion that it is possible to identify, separate and evaluate the spatial as an independent phenomenon or a property of events examined through spatial analysis" (Sack 1974, p. 1). In the 1950s and $60 \mathrm{~s}$, space was widely considered to be the neutral backdrop against which human activities are deployed. This account of dimensional space ushered in the rise of quantitative geography. According to Fotheringam, Brunson, and Charlton, quantitative geography concerns the following activities: "the analysis of numerical spatial data; the development of spatial theory; and the construction and testing of mathematical models of spatial processes" (Fotheringam, Brunson, Charlton 2000, p. 11). Through a broad application of mathematical and statistical tools, graph theory, and more recently, sophisticated network analysis (where places are conceived as "nodes" occupying certain "positions"), geography was shaped as a positivist science that searches for the general in the particular. Moreover, quantitative geography was designed to produce impacts at the policy-making level. Transport geography, for instance, accompanied the massive development of traffic infrastructure both in the United States and in Europe after the Second World War. ${ }^{2}$ It was a far different account of geography than the former, more idiographic one, which could be summed up in Chesterton's claim that geography should render the singularity of places through description: "A place is not an abstraction, but an actuality" (Chesterton 1950, p. 217). Quantitative geography based on spatial separatism, while overcoming the idiographic account of geography as the science of places (Vidal de la Blache 1922), fails to provide any historical or cultural understanding of the nodes implicated in the envisaged relations, namely places. The positivist approach,

\footnotetext{
${ }^{2}$ In order to approach transport geography from both an historical and theoretical point of view, see. Jean-Paul Rodrigue (2020).
} 
despite its unquestionable merits, sets aside the complex dialectics between spaces, places, and human experiences and practices to reach its scientific goals.

Both Malpas and Casey have deconstructed the genealogy of the positivist conception of space to demonstrate how space derives from the experience of being emplaced. Their assumption is as strong as it is simple: for human beings, being always implies being in a place. This means that geographical knowledge, which makes use of concepts such as space and place, develops from a primary set of spatial experiences. Strictly speaking, as Agnew points out, we should speak of two meanings of place: on the one hand, abstract spatial analysis "tends to view places as nodes in space simply reflective of the spatial imprint of universal physical, social or economic processes" (Agnew 2011, p. 317) and, on the other hand, place is a "distinctive coming together in space" (Ibidem), qualitatively unique. Agnew considers the notion of place as a distinct togetherness in space to be "phenomenological” (Ibidem). Humanistic geographers such as Yi-Fu Tuan (1971, 1977), Anne Buttimer (1976, 1994), and Ed Relph (1977), David Seamon (1979) put an emphasis on the qualitative relationship between individuals, cultures, and place as well. They used phenomenology as a counterpoint to the tenets of positivism, by focusing on the priority of the experience of places over absolute space. But only rarely did these humanistic geographers remember that Husserlian phenomenology is primarily a method that aims to ground science on experience, not to delete science on behalf of the alleged ineffability of experience. At times, these humanistic geographers of the 1970s ended up espousing existentialism or, in the words of Pickles, "naiive subjectivism" (Pickles 1985, p. 68). Some critics have denounced their version of phenomenology as superficial and psychologistic. These criticisms might be ungenerous, when addressed to the genuine arguments of humanistic geographers. Nonetheless, between the lines of the fiercest criticisms towards them lies the concern that, through its emphasis on the "existential grounding of human life", a strictly idiographic, premodern, reactionary notion of place comes back in through the window after having been put out through the door. Human geographer John Agnew explains the risks of the idiographic conception of place as follows:

Living in place, from this point of view, is akin to stepping into a Thomas Kinkade painting and enjoying the unselfconscious sociability of a world long since lost. Today, as we all bowl alone and look back nostalgically on the world we have lost, place takes on a misty glow as a concept whose shelf life has long since run out. This putting place in the past has made it next to impossible to argue the merits of place as a concept with any sort of theoretical equivalence to those such as class, status, nation, state and firm (Agnew 2011, p. 323).

A growing part of geographers in the last decades have expressed dissatisfaction towards the binary opposition between space and place. The juxtaposition of space, as the pure objectivity of the existent, and place as a set of psychological meanings connected to specific portions of space by human subjects, may be misleading 
and confusing. ${ }^{3}$ Not only it reduces space and place to the increasingly contested dualism of subject and object, but also of nature (space as what is already there for humankind) and culture (places as sites characterized by social and symbolic meanings). Finally, both absolute space and idiographic place look politically suspect: on the one hand, through absolute space, lived environments are standardized and reduced to mere sites suitable for economical exploitation or "irrational land use" (Mazúr 1983, p. 140); on the other hand, localism, chauvinism and nationalism may return in disguise through idiographic place.

Human geographers, anthropologists, landscape researchers, architects, sociologists, and philosophers have engaged in various disputes over how to solve the 'space and place conundrum.' Even though a relational conception of both space and place has gained prominence, especially within human geography and cultural anthropology, the ways in which the relation between human practices, space, and place can be intended are manifold and, in some cases, conflicting.An interesting model is represented by the radical and postmodern geographies of 1980s, 1990s and 2000s. They emerged in the wake of post-structuralism and constructivism in social sciences, in reaction to both the idiosyncratic and premodern conception of place and the modernist account of spatial separatism. ${ }^{4}$ Post-structuralism does not consider space as objective anymore: rather, it is seen as "a palimpsest whose 'real' or 'authentic' meanings can somehow be recovered with the correct techniques, theories, or ideologies" (Cosgrove and Daniels 1988, 8). In this framework, mapping space no longer means revealing the inherent order of things, but rather imposing a representational order over space. What is given to sight is not an objective reality: on the contrary, human gaze always has its own codes through which space is framed. The lived perceptions and experiences that people can make of both natural and human environments are seen as largely representational: they are possible thanks to the mediation of cultural images which, at the same time, filter and cover the real state of socio-economic relationships. By underlining the constructed character of both space and place, post-structuralism solves the dualism of space and place by reducing both of them to their representations.

\footnotetext{
3 "this is an unnecessary and misleading separation/distinction that reduces the meaningfulness of both space and place" (Soja 1996, p. 40).

${ }^{4}$ Their scope is to show in various ways that social interactions produce space, and, in turn, spatial configurations give shape to everyday life at both material and cognitive levels (Lefebvre 1992, Soja 1996). Whereas places are often considered to be symbolic dimensions, whose meanings are shared by a community and passed on from one generation to another, spatial practices such as walking are seen as ways to reinterpret, revitalize and even challenge them (De Certeau 1984). In this argumentative framework, both absolute space and isolated place are challenged by lived and embodied practices, which always entail an experienced spatial dimension. To the social scientist influenced by both Marxism and phenomenology, space appears to be "constituted through social relations and material social practices" (Massey 1994, p. 254). Such an account of space entails a coherent conception of place. On the one hand, space is no longer absolute because its structure and meanings always depend on human and social interactions; on the other hand, places are viewed as "contingent and tied into a broader context" (Hubbard, Kitchin, Bartley, Fuller 2005, p. 17). The uniqueness of place "derives not from some mythical internal roots nor from a history of isolation (now to be disrupted by globalization), but precisely from the absolute particularity of the mixture of influences found together there" (Massey 1999, p. 22).
} 
It has been argued that, while overemphasizing representation, this solution disregards "the material compositions and conduct of representations" (Dewsbury et al. 2002, p. 438). To avoid this error, some authors found it useful to refer back to the notion of landscape, which endows a materiality often overlooked in contemporary spatial theories. Such a retrieval has been put forward by the so-called nonrepresentational approaches in geography and performance studies in the last twenty years (Thrift 2007). According to non-representational approaches, space is always in the making: it "takes shape and gains expression in shared experiences, everyday routines, fleeting encounters, embodied movements, precognitive triggers, practical skills, affective intensities, enduring urges, unexceptional interactions and sensuous dispositions" (Lorimer 2005, p. 84). As a consequence, the subjectivity of places and the objectivity of space are not refused, but rather dialectically interconnected into the processual reality of landscape. The non-representational approach shifts its emphasis to practices such as walking, driving, watching, travelling, and working, understood as "embodied acts of landscaping" (Lorimer 2005, p. 85). Here, landscape is the open result of the ongoing process of landscaping, which include both an objective and a subjective dimension. On the one hand, place meanings, far from being merely subjective or psychological, are embodied in space so that a material heritage is produced. Places owe their relative stability to this process of material fixation, which provides human action with a relatively objective backdrop. On the other hand, space, far from being merely objective, is continuously shaped by intersubjective practices of landscaping. Space owes its relative instability to the human subject's capacity to reinterpret and redraw places by means of new material inscriptions into landscape. Stability and instability, as well as objectivity and subjectivity, dialectically coexist in landscape.

The non-representational label does not refer to a theoretically coherent corpus of concepts, but rather it is "an umbrella term for diverse work that seeks better to cope with our self-evidently more-than-human, more-than textual, multi-sensual worlds" (Lorimer 2005, p. 83). However, many authors have engaged in identifying the philosophical sources of non-representational approaches, with a view to strengthen their theoretical assumptions. For instance, John Wylie has noted that the first nonrepresentational researches have been pursued "within a Deleuzian idiom of force, vitality, materiality, and relationality" (Wylie 2010, p. 104). Now, the point I want to make is that the emphasis on the material and mediating nature of landscape, typical of recent non-representationalist approaches, is not a complete novelty, but rather a revival of the morphological roots of geography. In fact, as I will show in the following, geography is allied to morphology by definition, therefore it challenges both objectivism and subjectivism. The retrieval of morphology's philosophical meanings and implications in the field of geography will help ground contemporary nonrepresentational intuitions about spatial practices on sounder philosophical basis.

\subsection{On the Tracks of a Morphological Interpretation of Landscape}

Morphology is usually defined as the part of geography that deals with the physical constitution of a portion of land and the processes which create it. The central 
elements of a landscape's morphology are mountains, hills, rivers, coasts, but also human settlements and works (Sauer 1925; Robinson 1977). The presence of both natural and anthropic elements, and their relative positions, constitute the real form of a landscape. In the history of the geographical ideas, however, morphology is commonly associated with physical geography, therefore it sets aside the anthropic elements, rather discussed in the field of human geography. In the context of physical geography, morphology is basically geomorphology (Tricart 1865, Ritchot 1975; Church 2010). A geomorphological approach to landscape is adopted when the scientific task consists in understanding the physical, geological, biological, chemical and climatical causes of its formation and transformation, and foreseeing possible evolving scenarios (Büdel 1963; Migon 2010). Geomorphology works through observation, mathematical models, and physical experiments. Typical morphological themes in physical geography include fluvial, aeolian, and glacial processes and land formation; quaternary environmental change and dating; hillslopes and soil erosion; coastal and marine processes, such as the formation of estuaries and lakes (Bierman, Montgomery 2014). It is nonetheless possible to talk of a "urban morphology" (Kropft 2007, Carlotti et al. 2017), when the task is to analyse a city's evolution from its formative years through its subsequent transformations ${ }^{5}$; or of "territorial morphology", 6 which deals with the relationship between a state's geographic shape, size, relative location, and its political situation. In this sense, a morphological approach, broadly used in physical geography, can be adopted by human geographers as well. However, in both cases of geomorphology and urban/territorial morphology, the aim is to explain why a geographical form looks the way it does. The actual shape of the landscape is, at the same time, the starting point, and the ultimate destination of the inquiry. Hence, accurate description and detailed survey of the considered geographical form is a fundamental part of the morphological stance. From empirical exploration to satellite mapping, the manners through which a landscape can be described and depicted have grown in precision and accuracy.

Nevertheless, if the descriptive side is overemphasized and isolated from the research of the causes and of the forces determining formation and transformation, morphology is reduced to mere topography, which can itself be defined as "the detailed written representation of a place or area including lakes, major rivers, mountains, valleys, latitudes and roads." (Aggie 2019). Of course, topographical insights are key for morphological inquiries. But a complete overlap of topography and morphology risks to overlook some of the philosophical implications held by the notion of morphology. Indeed, morphology is more than mere objective description; or better, morphological description is not just the neutral recording of what is there. Accurate and clever morphological description takes on philosophical senses concerning the epistemological position hold by the researcher towards the

\footnotetext{
${ }^{5}$ Urban morphology is a complex discipline whose main tenets have been laid out in the wake of the morphological ideas of authors such as Lewis Mumford in US (see Koritz 2004) and René Thom in France (see Farmer 2010). There is a flourishing tradition in urban morphology in France: an overview is provided by Albert Levy (2005).

${ }^{6}$ https://www.arcgis.com/apps/Cascade/index.html?appid=b6fd073621f5462e86b953142ed809e6.
} 
considered form, the characteristics of the bonds linking the form's constitutive elements (among which there are also human communities), the processual and temporal nature of its formation and transformation, its aesthetical and even moral meanings. Morphological description implies a committed way of looking upon nature as an all-encompassing, self-expressive whole, at the same time one and endlessly varied. From this view of nature as a living organism, borrowed from Goethe and Alexander von Humboldt, comes a certain sense of the word "form": an embodied and emplaced realization of nature, which nonetheless is organically interconnected with the other forms and which owe to this interconnection its constant, more or less subtle change. This ecological understanding of nature, enshrined in the folds of morphology, has an impact on the conceptualization of the geographical notions of space, place, landscape: and, of course, on how we think the position of the human subject in relation to space, place and landscape. The philosophical character of morphology derives from Goethe's scientific approach towards nature and especially organic life. In this sense, morphology implies an anti-reductionist, non-mechanist view of nature, in opposition to the Cartesian-Newtonian mechanist approach (Bortoft 1996; Holdrege 2005; Weik 2017).

The first geographer who seemed to be aware of the philosophical connotation of the term morphology was Carl Sauer, who wrote The Morphology of Landscape in 1925. Despite his unquestioned position in the pantheon of the most influential geographers of twentieth century, referring to Sauer today can seem outdated, as he and his Berkeley School legacy have been largely criticized and disregarded. During the hegemony of positivist geography, the morphological notion of landscape might be seen as retrograde and reactionary. The descriptive approach of Sauerian morphology appeared to be incompatible with theoretical aims, such as framing spatial organisation in terms of patterns and processes (Ackermann 1962), discovering spatial laws (Harvey 1969) and highlighting the mechanisms of cognitive mapping (Golledge 1981). The practice of surveying, at the very heart of Sauer's approach, has been dismissed as "bumbling amateurism and antiquarianism" (Gould 1979, p. 140). More recent trends in cultural geography have considered Sauer's cultural conception to be super-organic (Duncan 1980), which leads to the accusation that it underestimates social factors in geographical explanation such as class and social stratification (Jackson 1989). Even the cultural geographers of the 1990s-2000s, who dealt primarily with the symbolic representations, meanings, and values of spaces and places, caricatured Sauer's descriptive approach as irrelevant and outdated. Many geographers drew profusely on phenomenology from the1970s onward, as a reaction to the hegemony of positivism, even misunderstanding it at times (Pickles 1985). However, very few acknowledged the phenomenological démarche of Sauer's work. For instance, according to Olaf Kühne, the Sauerian conception of landscape relied chiefly on 'the 'physiognomic' tradition of the versatilely interested traveller combined from a 'naïve' world view and 'scenic eye"' (Kühne 2019, p. 69). The morphological traits of Sauer's geography have been largely overlooked or misunderstood. As a result, the term 'morphology' in the field of geography was progressively deprived of its philosophical significance.

A retrieval of Sauer's work is useful because he invoked the concept of landscape to endow the conjunction between space and place with a materiality that is perhaps 
missing from much of the current literature on emplacement in relation to space. It is worth noticing that, from a logical point of view, landscape is not conceived as the result of the mediation between the universal (space) and the particular (place). On the contrary, in landscape Sauer sees the first and proper object of geography: starting from it, one can delimit smaller regions characterized by specific physical and symbolic orders, and call them idiographic places; or, one can take into account its mathematizable features and produce the abstraction of absolute space. Sauer's aim is to better determine the scientific status of geography as a distinct and non-reducible discipline. In his seminal paper The Morphology of Landscape (1925), Sauer adopts a phenomenological view of science to prevent the reduction of geography to earth science and physics. A phenomenological account of sciences entails that different and autonomous fields of knowledge can be articulated according to their concern with given categories of phenomena, which stand in various relations with each other but that cannot be reduced to any other. In other words, sciences, phenomenologically understood, follow an articulation which springs from "the experience of mankind, not the inquiry of the specialist" (Sauer 1996, p. 298). Geography must be acknowledged as an autonomous science for it concerns a specific set of phenomena and experiences that cannot be reduced or subsumed under other sets. Geographic knowledge cannot be reduced to earth science in the name of the search for a general law regulating geological processes: rather, geographical knowledge "presupposes the general properties and processes of the earth, or accepts them from other sciences; for its own part, it is oriented about their varying areal expressions" (Hettner 1923, p. 37). ${ }^{7}$ Sauer adopts the anti-reductionist standpoint of the influential German geographer Alfred Hettner and claims that geography, at its very heart, is neither idiographic nor nomothetic. This methodological specificity challenges the typically Neo-Kantian distinction between the objectivity of the natural sciences and the subjectivity of the cultural ones. Geography deals with areal variations and connections. It is "chorology" as opposed to "general earth science." ipates the objection according to which regional description is inadequate to reach a standard scientific level. Geographical phenomena "are not simply assorted, but are associated, or interdependent" (Sauer 1996, p. 299). In geography "the competence to arrive at orderly conclusions is not affected in this case by the questions of coherence or incoherence of the data, for their characteristic association, as we find them in the area, is an expression of coherence" (Sauer 1996, p. 299). Besides, time has an important role in the association and the variation of geographical facts and phenomena; but it does not operate as "a term for some identifiable causal relation" (Sauer 1996, p. 299). The diachronic dimension of time is therefore needed, in order to deal with spatial transformations which do not necessarily follow rigid patterns, but include unpredictable changes. All of this does not mean that geography cannot reach scientific standards. Geography just has different standards that do not consist in the individuation of regular laws.

\footnotetext{
7 Hettner is quoted in Sauer 1996, p. 299.

8 The two classic models of the struggling viewpoints are Strabo's Geography, which put emphasis on regions and their variations, and Ptolemy's Geography, which argued for a holistic view of earth.
} 
According to Sauer, geography has as its specific objects differentiated regions understood as forms. Sauer's chorology is a morphology. Therefore, he preferred to speak of landscape rather than, more generally, region. In fact, geography's characterizing object is landscape: not one or another element of landscape, which can be separated from the others and subsumed under a different explanatory order (vegetation under botany, soil under pedology, animals under zoology, cities under urbanism or architecture), but landscape as a whole: as a form which keeps together different kinds of elements in a concrete and visible order. In this sense, landscape cannot be explained by its reduction to its elementary components, as a classic analytical thought would do. On the contrary, elements can be properly understood only by considering the part they play within the greater environment to which they belong. They can be grasped as landscape elements because, all together and through their interactions, participate to the larger undertaking of landscape formation and transformation.

Landscape can be understood as a form in the Goethean sense, for it is a whole of interrelated and interdependent parts, it is transformed in time, it is an immersive reality which encompasses its inhabitants and its observers. The notion of form is implicit in the very term landscape: "Landscape is the English equivalent of the term German geographers are using largely and strictly has the same meaning, a land shape, in which the process of shaping is by no means thought of as simply physical. It may be defined, therefore, as an area made up of a distinct association of forms, both physical and cultural" (Sauer 1996, p. 300). This idea, which concerns the content of the discipline, also challenges the modern division of knowledge into the natural sciences and the cultural sciences. By occupying the threshold between nature and culture, landscape shows the precariousness of the two realms' borders, hinting at the possibility that both nature and culture, in their pure forms, are but abstractions.

Sauer also affirms that landscape is a generic concept, indicating a kind of interrelation of material and symbolic components, which finds actualization in different scenes ('this' or 'that' landscape). This provides geography with a certain degree of generalization to counterbalance the undeniably idiographic trait of the discipline. Geography describes landscapes in their variety and diversity, but still, it understands themas landscapes, namely, as organic associations of natural and cultural facts and processes. This precision allows Sauer to question Croce's idea that "the geographer who is describing a landscape has the same task as a landscape painter" (Sauer 1996, p. 300). According to the morphological approach, landscape as an association of material and symbolic facts and processes is not primarily the correlate of an aesthetic gaze. Others have considered landscape as the object of a favourable and idealized contemplation of the past. This reduction of landscape to image has been accused of political intentions. For instance, in the case of the English art historian Hoskins, landscape is a rural idyll intrinsically menaced by "the threat of imminent destruction or obliteration" (Wylie 2007, p. 36) and disfigured by "the villainous requirements of the new age" (Hoskins 1995). ${ }^{9}$ The aesthetic interpretation

\footnotetext{
${ }^{9}$ Hoskins is quoted in Wylie 2007, p. 34.
} 
of landscape must be understood as a postulate of the modern division between the pure eye of the subject and nature as pure object. ${ }^{10}$ In the gaze of the allegedly pure subject, landscape is nothing but a visual panorama, external to the subjectivity. On the contrary, from a non-representational perspective, anticipated on this point by Sauer's morphological work, landscape comes back to life and reverts to its organic nature. Landscape's aesthetic character does not only concern the eye, but it encompasses and embraces the inhabitants, stimulates the curiosity of the researchers, and boosts the imagination of the travellers. In landscape, cultural symbols are embodied in spatial artefacts and dispositions which require description, recording and, if needed, decoding. The process of geographical knowledge constitutively includes fieldwork as a defining hallmark: "Being afoot, sleeping out, sitting about camp in the evening, seeing the land in all its seasons are proper ways to identify the experience, of developing impression into larger appreciation and judgement. I know no prescription of method; avoid whatever increases routine and fatigue and decreases alertness" (Sauer 1956, p. 296). The total reality of landscape calls for an immersive experience which undoubtedly has aesthetic value. Morphology ensures a connection between aesthetic experience and scientific knowledge. Indeed, "The best geography has never disregarded the aesthetic qualities of landscape", revealing "a symphonic quality in the contemplation of the areal scene" (Sauer 1996, p. 311). Landscape, the very object of geography, deserves "a quality of understanding at a higher plane which may not be reduced to formal process" (Sauer 1996, p. 311).

One more thing has to be mentioned about Sauer's conception of morphological landscape. It has to do with one of its most narrow and qualified criticisms, namely, its adoption of a super-organic notion of culture. It is true that Sauer grants humanity a special place among the forces which give shape to the environment: "Cultural landscapes (...) are derived in each case from the natural landscape, man expressing his place in nature as a distinct agent of civilization" (Sauer 1996: 307). It is also true that culture seems to impose its will upon nature as an external force: "The cultural landscape is fashioned out of a natural landscape by a culture group. Culture is the agent, the natural area is the medium, the cultural landscape the result" (Sauer 1996, p. 307-308). However, as Mathewson noticed, "there is little evidence that Sauer, or most of his students for that matter, did accept Kroeber's super-organic concept" (Mathewson 2009: 16). On the one hand, it must be recognized that Sauer's focus on culture rather than on active and even conflictual social forces reflects a Spenglerian background, which typically conceives cultures as organic totalities (Gade 2009, p. 36-37). On the other hand, it should be remembered that Sauer's main opponent was the environmental determinism of early twentieth century. What is explicitly countered in The Morphology of Landscape is the idea according to which environment determines culture: "The earliest term was 'environmental control'. This was succeeded by 'response', 'adjustment' (...). All these positions are mechanistic. In

\footnotetext{
10 This is the thesis of French geographers such as Claude Raffestine (2005) and Augustine Berque (2013). It should be noted that, in Latin languages such as French and Italian, landscape is translated as "paysage" "paesaggio", which includes the term "paese", used in 1500 to refer to landscape painting. About this issue, see at least Assunto 1973 and D’Angelo 2009.
} 
some way they hope to measure the force that physical environment exerts over man. (...) The aim, therefore, is to make of geography a part of biophysics, concerned with human tropism" (Sauer 1996, p. 314). Morphology is the answer to the difficulties of mechanism in geography. Culture, and human behaviour in general, can hardly be reduced to mechanic responses to environmental stimuli. By asserting that "the direct influence of environmental stimuli is purely somatic" and that "what man does in an area because of tabu and totemism or because of his own involves use of environment rather than the active agency of the environment" (Sauer 1996, p. 314-315), Sauer breaks the causal bond between environmental determination and cultural achievements, paving the way for more advanced and less misleading definitions of culture. To recognize human agency over the environment does not necessarily imply that humans are placed in a position of detachment or exploitation. The conceptual challenge consists precisely in balancing the active role of man in inquiring, seeing, and shaping landscape with its position of "being-in", belonging with landscape, understood as the unity of material and symbolic environment of human life. However, the genetic approach of morphology necessarily leads to the recognition of the forces that unrelentingly give shape to the land. Morphology in the Goethean sense is always a morphogenesis. From this point of view, the very expression 'cultural landscape', which has been officially included in the World Heritage Committee's operational guides in 1990s, implies an insight about how cultures have progressively given shape to the environment by producing buildings, artefacts, streets, cultivations, arranged according to certain spatial dispositions.

From a conceptual point of view, an updated morphological approach to landscape can reformulate the relationship between space and place by avoiding the oppositional scheme of 'space-universal-abstract vs place-particular-concrete.' As mentioned above, this entails deep consequences on how to conceptualise both space and place. In the conclusion of my paper, I will offer some ideas to this end.

\subsection{Space and Place: a Morphological Account}

In the second paragraph, I have addressed two opposed and equally unilateral views of geographical concepts: on one side, in the framework of spatial separatism, space is conceived as the neutral receptacle where social processes occur. On the other side, the idiographic account of place tends to consider space as a scientific fiction and places as merely subjective and cultural. To put it bluntly, the nomothetic, positivist notion of space reduces singularities to abstract universality, whereas the idiographic notion of place disregards universality and openness to emphasize the irreducible status of the singular place, that corresponds with a specific living community. In the spirit of the Goethean morphology, as I have shown in the third paragraph, it is incorrect to divide the geographical world in two parts, an objective and natural one (space) and a subjective and cultural one (place): rather, it seems to be more appropriate to redefine them in a way which is consistent with the idea of nature as a dynamic whole to which humans fully participate. Such a direction crosses path with the notion of landscape: a term of mediation of space and place, subject and object, real and ideal: 
"landscape as a milieu in which the 'cultural' and natural' are mutually and indissolubly entangled and emergent via lived practices", as remarked by landscape theorist John Wylie (2011, p. 313).

In the recent geographical literature, Goethe and morphology have been rediscovered and integrated into a rejuvenated phenomenological project by David Seamon. The author maintains that Goethe's way of science must be understood as a "phenomenology of nature" and, therefore, it fosters "a deeper openness towards nature" (Seamon 2005, p. 86-87). Thanks to the model provided by Goethean morphology, place can be thought as an open form, constituted by a certain degree of closure and a certain degree of border porosity. Besides, by adopting the Goethean way to science, Seamon's phenomenological account of place challenges both objectivism and subjectivism:

On one hand, place is pictured 'objectively' as a spatial and environmental 'container' in which human life unfolds; on the other hand, place is pictured 'subjectively' in terms of individual or group feelings, attachments, cognitive representations, and so forth. A phenomenological understanding of place contends that objective and subjective aspects of any particular place and place experience are presupposed by and only possible because of the inescapable existential fact of an always-already lived emplacement that is one existential grounding of human life (Seamon 2018, p. 49).

In this sense, Seamon's concept of place may collect the legacy of the philosophical meaning of morphology, connected as it is with phenomenology. In Goethe's morphology, the direct observation of natural phenomena entails acknowledging forms in their self-expression and manifestation. It is not about meanings and senses accorded by human mind to extended nature, in itself devoid of any expressivity and meaningfulness: rather, it is nature which produces forms, senses, meanings, and conveys them to human subjects, who, in turn, recognize themselves as being fully part of a greater nature. Neither mere objectivism and realism, nor psychologism and mentalism suit Goethean morphology.

Seamon's conception of place is consistent with the morphological notion of landscape. Moreover, as explained above, the term 'landscape' includes a material, therefore objective dimension that the term 'place' does not take into account. In this sense, it is fair to argue that landscape is the mediation term between the objective (space) and the subjective (place), taken as a whole. As a conclusion of this paper, I will sketch the main characteristics of landscape according to a morphological perspective stemmed from Goethe:

- Internal cross-references: a landscape speaks about itself in its different parts. Its elements bring with them the hallmarks of the place to which they belong. A landscape owes its singularity and unicity from the deep co-integration of its elements. To understand this interrelation, mere objective mapping might not suffice. This is why landscape has always been also a matter of artistic painting. Far from being just a creative exercise of the painter, landscape painting had the 
scope of grasping and representing the peculiar form of the landscape and the living connection between its elements (Carus 2002; von Humboldt 2010). ${ }^{11}$

- Intuitive distinctiveness: a landscape can be considered unique by means of certain images we attach to it. Place is a matter of sense: we can feel its unity internally and represent it externally by means of a peculiar complex of symbols and images. Landscape consists in the "being expressive and visible" of place. This is also why landscapes elicit emotional responses and aesthetic judgements that vary over time. $^{12}$

- Dialectical relation with its inhabitants, considered as the proactive elements of the form. On the one hand, once established, the sense(s) of a place constitute(s) a tradition and are passed down the new generations of inhabitants. It is possible to speak of place as an encompassing dimension for the subject. ${ }^{13}$ On the other hand, spatial practices, from the most elementary, such as walking, to more complex ones, such as travelling, establishing institutions and businesses, migrating, and down to the more sublimated, such as representing a place in a poem or in a painting, all result in a series of micro-consequences on place's configuration ${ }^{14}$ and trigger its slow but relentless change. The dialectics of spatial movement and sense of place produces landscape, which must be intended as an open and ongoing process through which place-identity is not simply repeated and replicated, but also constantly reinterpreted and rewritten.

- Porousness of the borders: one landscape is never really isolated from others. Borders are always crossed by certain classes of subjects. ${ }^{15}$ The influence of a landscape on another one is brought about by all types of contact between different local communities, from the most pacific ones such as pictures diffusion and exchange (to see the postcard of an unknown landscape) down to the most violent as colonization and gentrification (to destroy landscape and to replace it with exotic recreations and predatory dispossessions, etc.).

\footnotetext{
${ }^{11}$ An important contribution about the connections and co-implications of mapping and painting has recently been offered by the philosopher Ed Casey (2002).

12 The issue of the aesthetic judgements about landscapes is a classic of philosophical aesthetics (Assunto 1973; Berleant 1997; D’Angelo 2010). The topic has strong practical impacts, as shown by quite a number of contributions in Environmental Management, Planning, etc. A morphological approach to landscape stresses the fact that landscape has its own expressivity, which elicits emotional responses from the part of the observers. Of course, landscape's expressivity is not imposed deterministically to the subject; rather, it enters into a dialectics with the subject's gaze, which is in turn historically and culturally determined. In other words, aesthetic judgement is neither objectivistic nor subjectivistic, but it is the complex outcome of the meeting between an expressive spatial reality and an affected and embodied subjectivity.

13 According to Malpas we should think "the subjectivity as essentially a function of place or locale" (Malpas 1998, p. 36).

14 This socio-spatial dialectics between practices and space has been discussed Michel de Certeau (1984), in a chapter entitled Spatial Practices (pp. 102 - 118), explicitly devoted to the ways in which everyday activities such as walking do not just repeat the spatial order but also trigger micro-changes that may usher into greater transformation. This intuition can be easily applied to the notion of landscape, which entails a stronger focus on materiality.

${ }^{15}$ According to Agnew, "nomads, travellers, temporary migrants, commuters and other itinerants (...) also define places (...) with which to rest and interact" (Agnew 2011, p. 327).
} 
- Space as horizon: an implication of the fact that no landscape is isolated, is that every place is, so to speak, emplaced in space. A single place can be seen as a living organism implanted in a wider environment which, extended to its maximum by progressive expansion, coincides with the earth. ${ }^{16}$ Therefore, space is not an absolute universality, but rather the encompassing dimension where the ongoing interaction between landscapes takes place.

Of course, the morphological solution to the 'space and place conundrum' would deserve greater elaboration. Nonetheless, we can already state that it indicates an innovative interpretation of the dichotomy space as universal / place as particular. The morphological approach suggests that space is not an abstract universality but rather the lived ecosystem encompassing all places in the earth. If each place can be considered as a processual and relatively stable form within space, space can be understood as a sort of limit-form that can never be apprehended intuitively. One can instead think of space in a negative way: it opens the boundaries which are constitutive of places and challenges the stable configurations of forms. In other words, space is that kind of universal endorsed by the Goethean morphology, always manifesting itself within non-permanent, but still accomplished singularities: places, in their variety and diversity. In the realm of this dispute between space and place one can also retrace the Goethean adage according to which "the particular and the universal do not confront each other across a chasm, but exist on the common ground where the particular turns into the universal and the universal back into the particular from moment to moment" (Cha 2015, p. 3). As a conclusion, I suggest that, according to the morphological account of space and place, space as horizon replaces space as empty receptacle, and place as "changeful home" (Sauer 1996, p. 315) replaces place as bounded realm. The concept which contains both space and place in a tensional unity answers to the name of landscape: a sensible association of natural and cultural forms in which a spatial possibility finds actualization.

Funding Open access funding provided by Università degli Studi di Torino within the CRUI-CARE Agreement.

Open Access This article is licensed under a Creative Commons Attribution 4.0 International License, which permits use, sharing, adaptation, distribution and reproduction in any medium or format, as long as you give appropriate credit to the original author(s) and the source, provide a link to the Creative Commons licence, and indicate if changes were made. The images or other third party material in this article are included in the article's Creative Commons licence, unless indicated otherwise in a credit line to the material. If material is not included in the article's Creative Commons licence and your intended use is not permitted by statutory regulation or exceeds the permitted use, you will need to obtain permission directly from the copyright holder. To view a copy of this licence, visit http://creativecommons.org/licen ses/by/4.0/.

\footnotetext{
${ }^{16}$ In this sense, morphology entails an ecological understanding of earth resulting from the philosophy of nature of Romanticism, shared by the forefather of modern geography Alexander von Humboldt. On his contribution towards an ecological understanding of the earth, see Egerton (1977) and Wulf (2015).
} 


\section{References}

Ackerman EA (1962) Public policy issues for the professional geographer. Ann Assoc Am Geogr 52(3):292-298

Agnew J (2011) Space and Place, in Agnew J and Livingstone D (ed.), The Sage Handbook of Geographical Knowledge, Sage

Assunto R (1973) Il paesaggio e l'estetica. Giannini, Napoli

Berleant A (1997) Living in the landscape: towards an aesthetics of environment. University of Kansas, Lawrence

Berque A (2013) Thinking through landscape. Routledge, Abingdon

Bierman P, Montgomery D (2014) Key concepts in geomorphology, Macmillan Higher Education.

Bortoft H (1996) The wholeness of nature: goethe's way of science. Floris Books, Edinburgh

Büdel J (1963) Klima-genetische Geomorphologie. Geogr Rundschau 7:269-286

Carlotti P, Camiz A, Díez C (2017) Urban morphology and design Joint research perspectives and methodological comparison. U+D Edition, Italy

Carus JG (2002) Nine letters on landscape painting: written in the years 1815-1824; with a letter from goethe by way of introduction. Getty Publications, LA

Casey E (2009) Getting Back into place: toward a renewed understanding of the place-world. Indiana University Press, Indianapolis

Casey E (1996) How to get from space to place in a fairly short stretch of time phenomenological prolegomena. In: Senses of place, Feld S and Basso K, School for Advanced Research Press, Santa Fe

Krapp A, Ryan RM (1997) The fate of place: a philosophical history. University of California Press, Berkeley

Lopez Bernal J, Cummins S, Gasparrini A (2002) Representing Place Landscape Painting and Maps. University of Minnesota Press, Minneapolis

de Certeau M (1984) The Practice of Everyday Life trans. California University Press, Berkeley, Rendall $S$

Cha D (2015) Goethe's World Literature Universal Particularism, and European Imperialism. CLCWeb: Compar Lit and C 17:4

Church M (2010) The trajectory of geomorphology. Progress Phys Geogr 34(3):265-286

Cosgrove D, Daniels S (1988) The Iconography of Landscape. Cambridge University Press, Cambridge

Cox KRRG, Golledge (1981) Behavioral problems in geography revisited. Methuen, New York

D’Angelo P (2009) Estetica del paesaggio. Il Mulino, Bologna

Dewsbury J-D, Wylie J, Harrison P, Rose M (2002) Enacting geographies. Geoforum 32:437-441

Duncan J (1980) The Superorganic in American Cultural Geography. Ann Assoc Am Geogr 70(2):181-198

Farmer Y (2010) Topologie et modélisation chez René Thom : l'exemple d'un conflit de valeurs en éthique. Philosophiques 37(2):369-386

Fii $\mathrm{F}$ et al (2012) What is landscape? towards a common concept within an interdisciplinary research environment. eTopoi J Ancient Stud 3:169-179

Fotheringham AS, Brunson C, Charlton M (2000) Quantitative Geography: Perspectives on Spatial Data Analysis. Sage, LA

Gade DW (2009) Thoughts on Bibliographic Citations to and by Carl Sauer. In: Denevan WM, Mathewson K (eds) Carl Sauer on Culture and Landscape. Louisiana State University Press, Baton Rouge, pp 29-52

Goethe J W (1985-98) Sämtliche Werke nach Epochen seines Schaffens Münchner Ausgabe (ed.) Karl Richter et al. Carl Hanser Verlag, Munich

Gould P (1979) Geography 1957-1977: the augean period. Ann Assoc Am Geogr 69:139-151

Eng. trans: The collected works. Scientific studies, Suhrkamp, New York, 1988 (1987)

Harvey D (1969) Explanation in geography. Edward Raynold, London

Holdrege C (2005) Doing Goethean science. Janus Head 8(1):27-52

Hoskins WG (1955) The making of the english landscape. Hodder and Stoughton, London

Hubbard P, Kitchin R, Bartley B and D. Fuller D (2005) Thinking Geography. Space, Theory and Contemporary Human Geography, Continuum, London-New York ( $2^{\circ}$ ed.).

Von Humboldt A (2010) Cosmos Sketch of a Physical Description of the Universe. Cambridge University Press, Cambridge

Jackson P (1989) Maps of Meaning. Unwin Hyman, London 
Jammer M (1954) Concepts of Space (with a foreword of A. Einstein), Harvard University Press, Cambridge (US).

Koritz A (2004) Urban form versus human function in the, 1920 Lewis Mumford and John Dos Passos. Am Stud 45(22):101-123

Kropf K (2009) Aspects of urban form. Urb Morphol 13(2):105-120

Kühne O (2019) Landscape theories a brief introduction. VS Verlag für Sozialwissenschaften, New York

Lefebvre H (1974) The production of space, transl. Dn N, Smith,

Levy A (2005) Formes urbaines et significations: revisiter la morphologie urbaine. Espaces et sociétés 122(25):48

Lorimer H (2005) Cultural geography: the busyness of being more-than-representational. Progress Human Geograph 29(1):83-94

Low S (2013) Spatializing culture the ethnography of space and place. Routledge, Abingdon

Malpas J (1998) Finding Place: Spatiality Locality and Subjectivity. In: A Light, J Smith Philosophies of Place, Rowman and Littlefield, Lanham

Zakharuk ZI et al (2018) Place and experience: a philosophical topography. Cambridge University Press, Cambridge

Massey D (1999) Power-Geometries and the Politics of Space-Time. University of Heidelberg, Heidelberg

Mathewson K (2009) Carl Sauer and his critics. In: Denevan W, Mathewson K (eds) Carl Sauer on culture and landscape. Louisiana State University Press, Baton Rouge

Mazúr E (1983) Space in geography. GeoJournal 7(2):139-143

Migon P (2010) Geomorphological landscape of the world. Springer, Netherlands

Neisser H (1959) The phenomenological approach in social science. Philos and Phenomenol Res 20(2):198-212

Petitot J (1985) Morphogenèse du sens I : Pour un schématisme de la structure. Puf, Paris

Pickles J (1985) Phenomenology science and geography. Cambridge University Press, New York

Raffestine C (2005) Dalla nostalgia del territorio al desiderio di paesaggio. Alinea, Firenze

Richards R (2002) The romantic conception of life. The University of Chicago, Chicago and London

Ritchot G (1975) Essais de géomorphologie structurale. Les Presses de l'Université de Laval, Laval

Robbins B (2015) The delicate empiricism of goethe: phenomenology as a rigorous science of nature. Indo-Pacific J Phenomenol 6(sup1):1-13

Robinson R (1977) Morphology and landscape. Harper Collins, New York

Rodrigue JP (2020) The geography of transport systems. Routledge, Abingdon

Sack R (1974) The spatial separatist theme in geography. Econ Geograp 50:1-19

Sauer S (1925) The morphology of landscape, University of California, Berkley. In: Agnew J, Livingstone DN, Rogers A (eds) Human geography: an essential anthology. Blackwell, Oxford

Bruns A (1956) The education of a geographer. Ann Assoc Am Geogr 3:287-299

Schutz A (1932) The Phenomenology of the Social World trans. Northwestern University Press, Evanston Seamon D (1979) A Geography of the Lifeworld. Croom Helm, London

Seamon D (2018) Lifes Takes Place Phenomenology Lifeworlds and Place Making. Routledge, New York Thrift N (2007) Non-representational theory: space Politics Affect. Routledge, London

Tricart J (1965) Principes et méthodes de la géomorphologie. Masson, Paris

Weik E (2017) Goethe and the study of life: a comparison with Husserl and Simmel. Cont Philos Rev 50:335-357

Wulf A (2015) The invention of nature: the adventures of Alexander von Humboldt, the lost hero of science. John Murray, London

Publisher's Note Springer Nature remains neutral with regard to jurisdictional claims in published maps and institutional affiliations. 